\title{
Association between lifestyle and musculoskeletal pain: cross-sectional study among 10,000 adults from the general working population
}

\author{
Jéssica Kirsch Micheletti ${ }^{1,2^{*}}$ (D) Rúni Bláfoss ${ }^{1,3}$, Emil Sundstrup ${ }^{1}$, Hans Bay ${ }^{1}$, Carlos Marcelo Pastre ${ }^{4}$ and \\ Lars Louis Andersen 1,5
}

\begin{abstract}
Background: Work-related musculoskeletal pain is a major cause of work disability and sickness absence. While pain is a multifactorial phenomenon being influenced by work as well as lifestyle, less is known about the association between specific lifestyle factors and the type of musculoskeletal pain. The aim of the study was to investigate if a dose-response association existed between lifestyle factors and musculoskeletal pain intensity in the low back and neck-shoulder.

Methods: Currently employed wage earners $(N=10,427)$ replied in 2010 to questions about work environment, lifestyle and health. Logistic regression analyses adjusted for various confounders tested the association of alcohol intake, physical activity, fruit and vegetable intake, and smoking (explanatory variables) with low back pain and neck-shoulder pain intensity (outcomes variables, scale $0-9$, where $\geq 4$ is high pain).

Results: The minimally adjusted model found that physical activity and fruit and vegetable intake were associated with lower risk of musculoskeletal pain, while smoking was associated with higher risk of musculoskeletal pain. In the fully adjusted model, physical activity $\geq 5 \mathrm{~h}$ per week was associated with lower risk of low back pain and neckshoulder pain with risk ratios (RR) of 0.95 (95\% Cl 0.90-1.00) and 0.90 (95\% Cl 0.82-0.99), respectively. No association was found between alcohol intake and pain.
\end{abstract}

Conclusion: Being physically active associated with lower risk of having musculoskeletal pain, while smoking habits and healthy eating were associated with higher pain when adjusting for age and gender. Considering the continuously increasing retirement age in many societies, initiatives to promote healthy habits should still be a political priority to help the workers to stay healthy and cope to their work.

Keywords: Musculoskeletal diseases, chronic pain, Low back pain, Neck pain, Exercise, health, smoking

\section{Background}

Low back pain and neck-shoulder pain affect between 51 and $90 \%$ and $14-71 \%$ of people at some point during their lifetime, respectively [1-3], and are the most common symptoms for seeking a physician [4]. Furthermore, low back pain and neck-shoulder pain are considered

\footnotetext{
* Correspondence: jessicamicheletti@hotmail.com

${ }^{1}$ National Research Centre for the Working Environment, Lersø Parkalle 105,

DK-2100 Copenhagen, Denmark

${ }^{2}$ São Paulo State University (UNESP), 305 Roberto Simonsen, Presidente

Prudente, Sao Paulo 19060-900, Brazil

Full list of author information is available at the end of the article
}

major public health problems that limit productivity at work and may have enormous medical and economic consequences on individuals, families, communities, industries and societies $[5,6]$. In 2013, low back pain and neck-shoulder pain accounted for the third-highest amount of health-care spending in the United States, with an estimated cost of $\$ 87.6$ billion [7]. Ferguson et al. [8] observed in a data set with nearly 2000 workers in various regions of the United States a prevalence rate of $25 \%$ for low back pain lasting at least 1 week. Considering the growing aging population in many societies, 
musculoskeletal problems are likely to increase, thus necessitating a better understanding of these disorders $[9,10]$.

Low back pain and neck-shoulder pain are multifactorial disorders related to both individual, physical and psychosocial work environmental factors [11]. In the past years, investigations of risk factors for low back pain and neck-shoulder pain among workers have been conducted in different parts of the world [12-19], and work factors such as hard physical work [20] and prolonged standing [21] have been identified as risk factors for musculoskeletal disorders. However, less is known about the consequences of poor lifestyle, such as low level of physical activity during leisure, smoking, alcohol intake and diet, in relation to low back pain and neck-shoulder pain.

Physical activity and exercise programs are increasingly being promoted and offered in various healthcare systems. A Cochrane review from 2017 [22] indicated that physical activity and exercise is an intervention with few adverse events being effective in decreasing low-back pain severity and physical function, and consequently improving quality of life. Therefore, more research is needed to observe the relationship of lifestyle factors with musculoskeletal pain.

Considering that cigarette smoking is one of the leading causes of premature morbidity and mortality [23], systematic reviews and meta analyses have been attempting to clarify its relationship with musculoskeletal disorders. In a review of association between smoking and low back pain, Stienen et al. concluded that [24] a high number of studies did not observe an association between smoking and low back pain. However, Shiri et al. [25] performed a meta-analysis and observed a stronger association between smoking and low back pain in adolescents than in adults. Few studies regarding the working population were included in this meta-analysis. A recent study from 2017 [26] with a sample of 60 painfree administrative workers of German universities, showed an increased risk of developing low back pain among the proportion of smokers.

Alcohol intake is another risk factor that needs to be considered. Few reviews have been carried out to investigate the association of alcohol intake with low back pain. In 2000, Leboeuf-Yde [27] performed a systematic review assessing the association between alcohol intake and the risk of developing a new episode of acute low back pain including 9 cross-sectional studies. The authors concluded that alcohol intake is not associated with low back pain. However, 2013 Ferreira et al. [28] performed another systematic review with a broader search strategy than that by Leboeuf-Yde et al. [27]. Twenty-six studies were included, and the results showed that alcohol consumption was associated with low back pain. However, this relation appears only to include complex and chronic low back pain and only generalizable to people with alcohol addiction.

Moreover, healthy lifestyle habits such as consumption of fruit and vegetables have also been investigated, however the number of studies is limited. This habit is considered as a part of healthy lifestyle behavior [29] or optimal lifestyle [30] defined by a combination of lifestyle factors and associated with the prognosis of low back pain [29]. In the study of Bohman et al. [29] with a sample size of 3938 men and 5056 women aged 18-84, an influence of healthy lifestyle behavior was observed on the prognosis of occasional low back pain. The results showed that the healthy lifestyle behavior is associated with decreased low back pain of long duration among women with occasional low back pain.

Altogether, more data is necessary to better understand the association between healthy lifestyle behavior and musculoskeletal disorders in workers. Because the working population is aging in many societies, a healthy lifestyle behavior may be important for staying healthy and cope to the work until high age. Thus, the present study aims to examine the joint association between four lifestyle behavior factors (physical activity, consumption of vegetables and fruits, alcohol intake and smoking) and musculoskeletal pain in the low back and the neckshoulder among more than 10,000 adults from the general working population in Denmark.

\section{Methods}

\section{Population}

The present study is a cross-sectional study consisting a questionnaire survey about work environment and health in the general working population in Denmark, the Danish Work Environment Cohort Study (DWECS) [31]. The questionnaire was sent out to approximately 20,000 working adults in 2010. A total of 10,605 workers (approximately 53\%) replied [32]. In this study, we included only currently employed wage earners from the 2010 round $(n=10,427)$, i.e. excluding self-employed people and people not affiliated with the labour market [33]. Because not all participants filled in all questions, the exact number for each analysis varies.

\section{Ethical approval}

The present study has been notified to and registered by The Danish Data Protection Agency (journal number 2015-57-0074). According to the Danish law, questionnaire- and register-based studies do not need approval by ethical and scientific committees, nor informed consent (Committee System on Biomedical Research Ethics, 2011; The Danish Data Protection Agency, 2008). All data were de-identified and analyzed anonymously. 


\section{Outcome variables}

\section{Low back pain and neck-shoulder pain intensity}

Low back pain and neck-shoulder pain intensity were assessed by replying to the question "Have you experienced any trouble (pain or discomfort) in your (body region) during the last 12 months?" on a scale ranging from 0 to 9 , where 0 is no pain and 9 is the worst imaginable pain. For further analyses, back pain was dichotomized into "High pain" (pain intensity $\geq 4$ ), "No or little pain" (pain intensity 0-3).

\section{Explanatory variables Physical activity}

Physical activity was assessed by the question: "How much time did you on average spend on each of the following leisure-time activities during the last year (including commuting to and from work)?"

It had the following three sub-questions of 1) low, 2) moderate and 3) high-intensity exercise: 1) "Walking, biking or other low-intensity exercise, where you do not get out of breath or sweaty (e.g. Sunday walks or lowintensity gardening)?" 2) "Exercise training, heavy gardening or fast walk/cycling, where you get out of breath and sweaty?" and 3) "Vigorous exercise or competitive sports?". The response options were: Do not perform this activity; $<2 \mathrm{~h}$ per week; $2-4 \mathrm{~h}$ per week; or $>4 \mathrm{~h}$ per week [34]. These four categories were recoded to $0,1,3$ or $5 \mathrm{~h}$ per week, respectively [34-36]. For the subsequent analysis, the hours of moderate and high-intensity exercise was summed and defined the weekly hours of exercise. As this variable is not strictly linear, we further categorized the sum of exercise into $0,1-2,3-4$, and $\geq 5$ $\mathrm{h}$ of moderate to high-intensity exercise per week.

\section{Alcohol intake}

Alcohol intake was assessed by two questions: (1) "How much alcohol do you drink on average on weekdays (Monday to Thursday)?", and (2) "How much alcohol do you drink on average Friday, Saturday and Sunday?" The amount of alcohol was considered as number of units per day. One unit = 1 bottle of beer, 1 glass of wine or 2 cl. liquor.

For further analyses, the number of units from the two questions were summed and further grouped into: "0-7 units per week"; "8-14 units per week"; "15-21 units per week"; ">21 units per week".

\section{Smoking status}

The smoking status was assessed by the following question: "Do you smoke?". The response categories were: (1) "Yes, daily"; (2) "Yes, sometimes"; (3) "Used to smoke but not anymore"; (4) "Have never smoked". For subsequent analyses, the answers were allocated to the following categories: "No, never," "Ex-smoker" or "Yes".
Furthermore, the quantity of smoking was assessed by the following question: "If you smoke, how much do you smoke per day on average?" The answers were allocated in the following groups: "0 cigarettes per day"; "1-9 cigarettes per day"; "10-20 cigarettes per day"; " $\geq 20$ cigarettes per day".

\section{Fruit and vegetable intake}

The consumption of fruits and vegetables were assessed by the following question: "How often do you eat fruit, salad / raw food, cooked vegetables - apart from potatoes?". The response options were: (1) "At least 3 times per day"; (2) "Twice per day"; (3) "1 time per day"; (4) "3-6 times per week"; (5) "1-2 times per week"; (6) "Rarer". For subsequent analyses, the response categories were divided into: " $\leq 2$ days per week"; "3-6 days per week"; "Daily".

\section{Control variables}

Control variables for the analyses in the present study included age (continuous, years) [37], gender (categorical: "male", "female") [37], body mass index (BMI) (continuous, $\mathrm{kg} / \mathrm{m}^{2}$ ), physical activity at work (categorical, "Standing or walking work with lifting tasks" and "Heavy and fast strenuous work) [38], psychosocial work factors (continuous scale from 0 to 100, single items on influence and emotional demands at work from the Copenhagen Psychosocial Questionnaire) [39], job group (categorical, information about 86 different job groups delivered by Statistics Denmark, e.g. office workers, school teachers, nurses) [33], and chronic disease (categorical) [40]. Chronic disease was based on the question, "Have you ever been informed by a physician that you have or have had one or more of the following conditions?" with the response options being "yes" and "No, never" to the following diseases: Depression, cardiovascular disease, and cancer.

\section{Statistics}

Using logistic regression analyses (PROC GENMOD of SAS version 9.2), the risk for high pain ( $\geq 4$ on a scale of 0-10) in the low back and neck-shoulder, respectively, was estimated. Risk ratios (RR) and 95\% confidence intervals $(95 \% \mathrm{CI})$ were calculated for high pain as outcome variable. Explanatory mutually adjusted factors were the four lifestyle factors. Model 1 was, besides the explanatory variables (healthy lifestyles), additionally adjusted for age and gender. Model 2 was, besides age and gender, additionally adjusted for BMI, physical activity at work, psychosocial work factors, job group, and chronic disease.

\section{Results}

Table 1 describes the characteristics of the study population. The proportion of female and male gender was 
Table 1 Demographics, lifestyle, and work-related and health characteristics

\begin{tabular}{|c|c|c|c|c|}
\hline & $\mathrm{N}$ & Mean & SD & $\%$ \\
\hline Age, years & 10,427 & 43.5 & 11.7 & \\
\hline BMI $\left(\mathrm{kg} \cdot \mathrm{m}^{-2}\right)$ & 10,095 & 25.4 & 4.4 & \\
\hline \multicolumn{5}{|l|}{ Gender } \\
\hline Men & 4762 & & & 45.7 \\
\hline Women & 5665 & & & 54.3 \\
\hline \multicolumn{5}{|l|}{ Smoking } \\
\hline No, never & 4897 & & & 48.2 \\
\hline Ex-smoker & 2916 & & & 28.7 \\
\hline Yes & 2356 & & & 23.2 \\
\hline \multicolumn{5}{|l|}{ Frequency missing $=258$} \\
\hline \multicolumn{5}{|l|}{ Physical activity at work } \\
\hline Mainly seated work & 4744 & & & 46.9 \\
\hline $\begin{array}{l}\text { Main standing/walking work, } \\
\text { not strenuous }\end{array}$ & 2425 & & & 24.0 \\
\hline $\begin{array}{l}\text { Standing/walking work with } \\
\text { lifting/carrying or heavy/fast } \\
\text { work, physically strenuous }\end{array}$ & 2952 & & & 29.2 \\
\hline Frequency missing $=306$ & & & & \\
\hline \multicolumn{5}{|l|}{ Psychosocial work factors (0-100) } \\
\hline Emotional demands & 10,154 & 44.6 & 25.1 & \\
\hline \multicolumn{5}{|l|}{ Frequency missing $=273$} \\
\hline Influence at work & 10,085 & 67.4 & 24.0 & \\
\hline \multicolumn{5}{|l|}{ Frequency missing $=342$} \\
\hline \multicolumn{5}{|l|}{ Depression } \\
\hline No & 8938 & & & 87.5 \\
\hline Yes & 1272 & & & 12.5 \\
\hline \multicolumn{5}{|l|}{ Frequency missing $=217$} \\
\hline \multicolumn{5}{|l|}{ Cardiovascular disease } \\
\hline No & 9719 & & & 95.2 \\
\hline Yes & 489 & & & 4.8 \\
\hline \multicolumn{5}{|l|}{ Frequency missing $=219$} \\
\hline \multicolumn{5}{|l|}{ Cancer } \\
\hline No & 9876 & & & 96.8 \\
\hline Yes & 331 & & & 3.2 \\
\hline \multicolumn{5}{|l|}{ Frequency missing $=220$} \\
\hline \multicolumn{5}{|l|}{ Low back pain } \\
\hline Low pain (0-3.9) & 7263 & & & 71 \\
\hline High pain (4-10) & 2964 & & & 29 \\
\hline \multicolumn{5}{|l|}{ Frequency missing $=200$} \\
\hline \multicolumn{5}{|l|}{ Neck-shoulder pain } \\
\hline Low pain (0-3.9) & 7156 & & & 70 \\
\hline High pain (4-10) & 3064 & & & 30 \\
\hline Frequency missing $=207$ & & & & \\
\hline
\end{tabular}

Legend: $N$ sample number, $B M I$ body mass index
54.3 and $45.7 \%$, respectively. Average age was $43.3 \pm$ 11.7 years, average BMI was $25.4 \pm 4.4$, and $46.9 \%$ had sedentary jobs while $53.1 \%$ had jobs with physically demanding job tasks. Low-intensity pain was most frequent in the low back and neck-shoulder region, with a prevalence of 71 and $70 \%$ for low back pain and neck-shoulder pain, respectively.

Table 2 shows the association between the four types of lifestyle behaviors with low back pain and neck-shoulder pain. The minimally adjusted model (model 1) showed that smoking and being physically active during leisure associated with higher and lower risk of pain in low back, respectively. Also, a daily intake of fruit and vegetables was associated with lower risk of having low back pain in the minimally adjusted model.

In the fully adjusted model (model 2), only a high level of physical activity (i.e. $5 \mathrm{~h}$ per week) was associated with lower risk of low back pain and neck-shoulder pain, with RRs of $0.95(0.90-1.00)$ and $0.90(0.82-0.99)$, respectively.

Estimates for the psychosocial factors that were used as continuous control variables (scale $0-100)$ are provided here (not discussed): For emotional demands, the OR's were 1.001 (95\% CI 1.001-1.002) for low back pain and 1.003 (95\% CI 1.002-1.005) for neck-shoulder pain, i.e. higher emotional demands is associated with higher pain. For influence at work, the OR's were 0.998 (95\% CI 0.998-0.999) for low back pain and 0.997 (95\% CI 0.996-0.998) for neck-shoulder pain, i.e. higher influence at work is associated with lower pain.

\section{Discussion}

The present study found that physical activity during leisure was associated with lower risk of having low back pain and neck-shoulder pain when adjusted for age and gender (model 1). Furthermore, when adjusting for age and gender, the level of smoking and physical activity were associated with higher and lower risk of low back pain and neck-shoulder pain, respectively. Daily fruit and vegetable intake was associated with low back pain when adjusted for age and gender, while no association was observed between alcohol intake and pain.

Physical activity is one of the most important characteristics for retaining health [41, 42], and inactivity is considered a major factor for developing various diseases [43]. In addition, there is evidence for using physical activity in the management of chronic low back pain [44]; however, there is still no consistent associations between the studies. Zadro et al. [45] performed a cross-sectional control study with 1588 twins from Spain. The authors evaluated self-reported recent low back pain (within the past 4 weeks), previous low back pain (no pain within the past 4 weeks), and persistent low back pain (no painfree month in the last 6 months). To evaluate physical activity level, the guidelines of the World Health Organization 
Table 2 Relative risk (RR) for having pain ( $\geq 4$ on a scale of $0-10$ ) in the low back and neck-shoulder, respectively, in relation to four types of health behaviors

\begin{tabular}{|c|c|c|c|c|c|c|}
\hline & & & Low back pain & & Neck-shoulder pai & \\
\hline & & & Model 1 & Model 2 & Model 1 & Model 2 \\
\hline & $\mathrm{N}$ & $\%$ & RR $(95 \% \mathrm{Cl})$ & RR $(95 \% \mathrm{Cl})$ & RR $(95 \% \mathrm{Cl})$ & RR $(95 \% \mathrm{Cl})$ \\
\hline Alcohol (un & Neek) & & & & & \\
\hline $0-7$ & 5308 & 52.6 & 1 & 1 & 1 & 1 \\
\hline $8-14$ & 2214 & 21.9 & $0.92(0.85-1.00)$ & $1.00(0.96-1.03)$ & $0.93(0.86-1.01)$ & $0.99(0.92-1.06)$ \\
\hline $15-21$ & 1270 & 12.6 & $0.96(0.87-1.07)$ & $1.00(0.95-1.04)$ & $0.93(0.85-1.03)$ & $0.97(0.89-1.05)$ \\
\hline$>21$ & 1306 & 12.9 & $1.06(0.97-1.17)$ & $1.01(0.97-1.06)$ & $1.03(0.94-1.14)$ & $1.01(0.93-1.11)$ \\
\hline Physical ex & ours pe & & & & & \\
\hline 0 & 1595 & 15.7 & 1 & 1 & 1 & 1 \\
\hline $1-2$ & 3688 & 36.4 & $0.84(0.77-0.92)$ & $0.96(0.93-1.01)$ & $0.93(0.85-1.01)$ & $0.97(0.89-1.04)$ \\
\hline $3-4$ & 2923 & 28.8 & $0.82(0.75-0.91)$ & $0.97(0.93-1.02)$ & $0.88(0.80-0.96)$ & $0.95(0.87-1.03)$ \\
\hline$\geq 5$ & 1938 & 19.1 & $0.83(0.75-0.93)$ & $0.95(0.90-1.00)$ & $0.86(0.77-0.95)$ & $0.90(0.82-0.99)$ \\
\hline Fruit and ve & intake & רcy) & & & & \\
\hline$\leq 2 / w k$ & 833 & 8.4 & 1 & 1 & 1 & 1 \\
\hline $3-6 / w k$ & 1330 & 13.4 & $0.98(0.86-1.11)$ & $1.01(0.95-1.07)$ & $1.06(0.92-1.21)$ & $1.06(0.94-1.20)$ \\
\hline Daily & 7734 & 78.1 & $0.87(0.78-0.97)$ & $1.00(0.95-1.05)$ & $1.00(0.89-1.12)$ & $1.06(0.95-1.18)$ \\
\hline Smoking (c & s pr day & & & & & \\
\hline 0 & 7813 & 77.3 & 1 & 1 & 1 & 1 \\
\hline $1-9$ & 717 & 7.1 & $1.18(1.05-1.32)$ & $1.04(0.98-1.10)$ & $1.10(0.98-1.23)$ & $1.03(0.93-1.14)$ \\
\hline $10-20$ & 912 & 9.0 & $1.22(1.11-1.35)$ & $1.04(0.99-1.09)$ & $1.16(1.05-1.28)$ & $1.05(0.96-1.15)$ \\
\hline$\geq 20$ & 667 & 6.6 & $1.38(1.24-1.54)$ & $1.05(0.99-1.11)$ & $1.33(1.19-1.48)$ & $1.10(0.99-1.22)$ \\
\hline
\end{tabular}

Model 1: Mutually adjusted for the 4 health behaviors + age and gender; Model 2: Mutually adjusted for the 4 health behaviors + age, gender, BMI, physical activity at work, psychosocial work factors (influence and emotional demands), job group, and chronic disease (depression, cardiovascular, cancer) Significant differences $(\mathrm{p}<0.05)$ are marked in bold

were used, which recommends at least 75 min of vigorousintensity physical activity, or at least 150 min of moderateintensity physical activity, per week. The authors observed an inverse association between recent low back pain and physical activity Conversely, when they controlled the analyses for genetics and shared environment, the association disappeared [45]. However, our findings indicate a lower risk for having low back pain when obeying to the recommendations of the World Health Organization.

Lunde and co-workers [46] performed a follow-up study of 6.5 years in young adults during the transition between school and work life. The authors aimed to investigate the association between low back pain and leisure time physical activity and they did not find trends of reduced low back pain with increased leisure time physical activity. However, the average age in the study was $17.5 \pm 1.2$ years, while the average age in the present study sample was $43.5 \pm 11.7$ years. Age could therefore be important since prevalence of low back pain seems to increase with aging [47].

Sitthipornvorakul and co-workers [48] published a systematic review to investigate the associations of physical activity with low back pain and neck pain.
Seven studies were included regarding neck pain, however, only one study investigated the associations in a working population. No association was found between physical activity during leisure time and neck pain. Ten high-quality studies were included concerning low back pain, but seven of the studies examined school children. The other three studies investigated a general population and found a relation between low back pain and levels of physical activity.

Another life-style habit that showed assotiations with low back pain and neck-shoulder pain was smoking status, however with adjustment for further covariates no associations were observed in the present study. Smoking could theoretically be a risk factor for developing chronic pain due to the nicotine which leads to an activation of the immune system [49]. The nicotine itself increases the degradation of collagen, decreases blood and oxygen supply, resulting in vascular damage predisposing to back pain, among other conditions [50]. However, the literature still is controversial. Considering low back pain, a cross-sectional study from 2017 investigated 1355 (741 males and 641 females) young Indian administrative service aspirants and medical postgraduate 
aspirants aged 18-35 years [12]. The results showed no associations between smoking and risk of low back pain. Another cross-sectional study from 2017 [18] investigated 358 male workers from Iran without finding any association between smoking and low back pain.

Both studies [12, 18] are somewhat in line with our findings with smoking not being a risk factor for having low back pain in the fully adjusted model used in this study. However, a study from 2018 [16] based on data of the 2009-2012 National Health Interview Survey (NHIS) of the civilian population of the United States did observe associations between self-reported low back pain and current or former smoking.

To our knowledge, the existing literature on neckshoulder pain seems to be in accordance with our study results. A study among software engineers observed an association between smoking and current neck pain [51]. Furthermore, a study of 19,665 community residents aged 18-65 years in China observed that the most common complaints of pain among the workers was pain in head, neck/shoulder and back. The study observed, that drinking and smoking status were significantly associated with increased reporting of chronic pain [52].

Considering the other lifestyle factors examined in the present study, neither alcohol nor vegetable and fruit intake showed a consistent association with low back pain and neck-shoulder pain in both the mutually adjusted models. A previous systematic review observed that an association between alcohol consumption and low back pain only appears in complex cases of low back pain and only in people with alcohol consumption addiction [28]. Regarding fruit and vegetable intake, fewer studies were conducted, and in general the evaluation occurred with a grouping analyses, as the study of Skillgate et al. [53]. They included similar healthy lifestyle behavior as the present study (physical activity, alcohol intake, smoking, and diet), and by means of a dichotomization (healthy/ not healthy) combined the variables in a categorical variable according to the number of healthy behaviors present. The authors explored the risk of low back pain and neck pain in both genders with the categorical variable and the results showed that a healthy lifestyle behavior seems to be protective for long duration low back pain and neck pain in men and women, respectively. This way of grouping variables is interesting, because pain is multifactorial.

Finally, it is important to note that the wide variation in prevalence of pain could be partially explained by methodological, racial/ethnical, or cultural differences [54]. Still, the differences between the two models used in the present study, with adjustment of covariates, indicate that low back pain and neck-shoulder pain are associated with several factors. Adjusting for several other factors in the second model reduced the association between lifestyle and pain, and only physical activity remained statistically associated with low back pain.

The present study has both limitations and strengths. A limitation of the study is the use of self-reported questionnaires, which may have led to reporting bias. For instance, there could be different understandings and perceptions in people with chronic pain, who often report problems with cognitive abilities, such as memory or attention [55]. However, a questionnaire survey is a relatively low-cost, easy-to-use tool for investigations on health behaviours among the general working population. Another limitation is that the observed results may in part be caused by reverse causation, i.e. people with higher levels of pain may tend to do less physical activity due to the pain. A strength of the study is the methodology used to perform the data analysis, where factors that might interfere with the results such as age, gender, BMI, physical activity at work, psychosocial work factors, job group, and chronic disease were controlled for. However, the control variables for chronic diseases do not consider diseases from respiratory and metabolic systems. Thus, future studies should look specifically into these factors. Another strength is the large sample size, including workers from diverse sectors representing the Danish workers in general, however, only 53\% of the invited workers replied the questionnaire. Nevertheless, a previous study performed a robustness analysis that showed that the rating of the working environment was only minimally influenced by the response rate even though the non-response analysis showed that the higher educated job groups had a higher response rate [33].

\section{Conclusion}

Being physically active during leisure associated with lower risk of having musculoskeletal pain, while smoking habits and healthy eating were associated with higher pain when adjusting for age and gender. Considering the relatively high prevalence of unhealthy habits in the general working population, initiatives to promote healthy habits should still be a political priority to help the workers to stay healthy and cope to their work.

\section{Abbreviations \\ 95\% Cl: 95\% confidence intervals; BMI: Body mass index; Cl: Confidence interval; DWECS: The Danish Work Environment Cohort Study; NHIS: National Health Interview Survey; OR: Odds ratio; RR: Risk ratios}

\section{Acknowledgements}

The authors are grateful to colleagues Elsa Bach and Ebbe Villadsen at NRCWE for valuable discussions and assistance with accessing data from the Danish Work Environment Cohort Study. This research received funding from the Danish Government (Finansloven [Finance Act]).

\section{Authors' contributions}

LLA and ES designed the study. JKM and RB drafted the manuscript. HB performed all statistical analysis. LLA, CMP and JKM contributed to interpretation of data. All authors have a substantial contribution on the conception of the work, critically revised the manuscript draft, approved the 
final version of the manuscript for submission and agreed both to be personally accountable for the author's own contributions and to ensure that questions related to the accuracy or integrity of any part of the work, even ones in which the author was not personally involved, are appropriately investigated, resolved, and the resolution documented in the literature.

\section{Funding}

This research received no specific grant from any funding agency in the public, commercial, or not-for-profit sectors.

\section{Availability of data and materials}

The datasets used and/or analyzed during the current study will be available from Professor Lars L. Andersen on a reasonable request.

\section{Ethics approval and consent to participate}

The present study has been notified to and registered by The Danish Data Protection Agency (journal number 2015-57-0074). According to Danish law, questionnaire- and register-based studies do not need approval by ethical and scientific committees, nor informed consent (Committee System on Biomedical Research Ethics, 2011; The Danish Data Protection Agency, 2008). All data were re-identified and analyzed anonymously.

\section{Consent for publication}

Not applicable

\section{Competing interests}

The authors declare that that one of the co-author, Lars Louis Andersen, is an Associate Editor for this journal.

\section{Author details}

${ }^{1}$ National Research Centre for the Working Environment, Lersø Parkalle 105, DK-2100 Copenhagen, Denmark. ${ }^{2}$ São Paulo State University (UNESP), 305 Roberto Simonsen, Presidente Prudente, Sao Paulo 19060-900, Brazil. ${ }^{3}$ Department of Sports Science and Clinical Biomechanics, SDU Muscle Research Cluster (SMRC), University of Southern Denmark, DK-5250 Odense, Denmark. ${ }^{4}$ Department of Physiotherapy, Univ Estadual Paulista (UNESP), 305 Roberto Simonsen, Presidente Prudente, Sao Paulo 19060-900, Brazil. ${ }^{5}$ Sport Sciences, Department of Health Science and Technology, Aalborg University, Aalborg, Denmark.

\section{Received: 9 September 2019 Accepted: 11 December 2019}

\section{Published online: 17 December 2019}

\section{References}

1. Airaksinen O, Brox JI, Cedraschi C, et al. Chapter 4. European guidelines for the management of chronic nonspecific low back pain. Eur Spine J Off Publ Eur Spine Soc Eur Spinal Deform Soc Eur Sect Cerv Spine Res Soc. 2006; 15(Suppl 2):S192-300.

2. Wieser S, Horisberger B, Schmidhauser S, et al. Cost of low back pain in Switzerland in 2005. Eur J Health Econ HEPAC Health Econ Prev Care. 2011; 12(5):455-67.

3. Global Burden of Disease Study 2013 Collaborators. Global, regional, and national incidence, prevalence, and years lived with disability for 301 acute and chronic diseases and injuries in 188 countries, 1990-2013: a systematic analysis for the Global Burden of Disease Study 2013. Lancet Lond Engl. 2015;386(9995):743-800.

4. Deyo RA, Weinstein JN. Low back pain. N Engl J Med. 2001:344(5):363-70.

5. Sundstrup E, Andersen LL. Hard physical work intensifies the occupational consequence of physician-diagnosed Back disorder: prospective cohort study with register follow-up among 10,000 workers. Int J Rheumatol. 2017; 2017:1037051

6. Murray C, Atkinson C, Bhalla K, et al. The state of US health, 1990-2010: burden of diseases, injuries, and risk factors. JAMA. 2013;310(6):591-608.

7. Dieleman JL, Baral R, Birger M, et al. US spending on personal health care and public health, 1996-2013. JAMA. 2016;316(24):2627-46.

8. Ferguson SA, Merryweather A, Thiese MS, et al. Prevalence of low back pain, seeking medical care, and lost time due to low back pain among manual material handling workers in the United States. BMC Musculoskelet Disord. 2019;20(1):243
9. Schaafsma FG, Anema JR, van der Beek AJ. Back pain: prevention and management in the workplace. Best Pract Res Clin Rheumatol. 2015;29(3): 483-94.

10. GBD 2013 DALYs and HALE Collaborators, CJL M, Sundstrup RM, et al. Global, regional, and national disability-adjusted life years (DALYs) for 306 diseases and injuries and healthy life expectancy (HALE) for 188 countries, 1990-2013: quantifying the epidemiological transition. Lancet Lond Engl. 2015;386(100009):2145-91.

11. Ariëns GA, van Mechelen W, Bongers PM, et al. Psychosocial risk factors for neck pain: a systematic review. Am J Ind Med. 2001;39(2):180-93.

12. Ganesan S, Acharya AS, Chauhan R, et al. Prevalence and risk factors for low Back pain in 1,355 young adults: a cross-sectional study. Asian Spine J. 2017; 11(4):610-7.

13. Garcia JBS, Hernandez-Castro JJ, Nunez RG, et al. Prevalence of low back pain in Latin America: a systematic literature review. Pain Physician. 2014; 17(5):379-91.

14. Malta DC, Oliveira MM, SSCA A, et al. Factors associated with chronic back pain in adults in Brazil. Rev Saude Publica. 2017;51(suppl 1):9s.

15. Son KM, Cho NH, Lim SH, et al. Prevalence and risk factor of neck pain in elderly Korean community residents. J Korean Med Sci. 2013; 28(5):680-6.

16. Yang $H$, Haldeman S. Behavior-related factors associated with low Back pain in the US adult population. Spine. 2018:43(1):28-34.

17. Noormohammadpour P, Mansournia MA, Koohpayehzadeh J, et al. Prevalence of chronic neck pain, low Back pain, and knee pain and their related factors in community-dwelling adults in Iran: a population-based National Study. Clin J Pain. 2017;33(2):181-7.

18. Rafeemanesh E, Omidi Kashani F, Parvaneh R, et al. A survey on low Back pain risk factors in steel industry workers in 2015. Asian Spine J 2017:11(1):44-9.

19. lizuka Y, lizuka H, Mieda T, et al. Prevalence of chronic nonspecific low Back pain and its associated factors among middle-aged and elderly people: an analysis based on data from a musculoskeletal examination in Japan. Asian Spine J. 2017;11(6):989-97.

20. Sundstrup E, Jakobsen MD, Brandt M, et al. Regular use of pain medication due to musculoskeletal disorders in the general working population: crosssectional study among 10,000 workers. Am J Ind Med. 2016;59(11):934-41.

21. Abolfotouh SM, Mahmoud K, Faraj $K$, et al. Prevalence, consequences and predictors of low back pain among nurses in a tertiary care setting. Int Orthop. 2015;39(12):2439-49.

22. Geneen L, Smith B, Clarke C, et al. Physical activity and exercise for chronic pain in adults: an overview of Cochrane reviews. Cochrane Database Syst Rev. 2017:4:CD011279.

23. Audrain-McGovern J, Benowitz N. Cigarette smoking, nicotine, and body weight. Clin Pharmacol Ther. 2011;90(1):164-8.

24. Stienen MN, Richter $\mathrm{H}$, Prochnow N, et al. Does smoking correlate with low back pain and the outcome of spinal surgery? Z Orthopadie Unfallchirurgie. 2011;149(3):317-23.

25. Shiri $R$, Karppinen J, Leino-Arjas $P$, et al. The association between smoking and low back pain: a meta-analysis. Am J Med. 2010;123(1):87 e7-35.

26. Mierswa T, Kellmann M. Psychological detachment as moderator between psychosocial work conditions and low back pain development. Int J Occup Med Environ Health. 2017:30(2):313-27.

27. Leboeuf-Yde C. Alcohol and low-back pain: a systematic literature review. J Manip Physiol Ther. 2000:23(5):343-6.

28. Ferreira PH, Pinheiro MB, Machado GC, et al. Is alcohol intake associated with low back pain? A systematic review of observational studies. Man Ther 2013;18(3):183-90.

29. Bohman T, Alfredsson L, Jensen I, et al. Does a healthy lifestyle behaviour influence the prognosis of low back pain among men and women in a general population? A population-based cohort study. BMJ Open. 2014; 4(12):e005713.

30. Pronk NP, Lowry M, Kottke TE, et al. The association between optimal lifestyle adherence and short-term incidence of chronic conditions among employees. Popul Health Manag. 2010;13(6):289-95.

31. Burr H, Bjorner JB, Kristensen TS, et al. Trends in the Danish work environment in 1990-2000 and their associations with labor-force changes. Scand J Work Environ Health. 2003:29(4):270-9.

32. Nabe-Nielsen $K$, Garde AH, Clausen T, et al. Does workplace health promotion reach shift workers? Scand J Work Environ Health. 2015: 41(1):84-93. 
33. Andersen LL, Fishwick $D$, Robinson $E$, et al. Job satisfaction is more than a fruit basket, health checks and free exercise: cross-sectional study among 10,000 wage earners. Scand J Public Health. 2017;45(5):476-84.

34. Calatayud J, Jakobsen MD, Sundstrup E, et al. Dose-response association between leisure time physical activity and work ability: cross-sectional study among 3000 workers. Scand J Public Health. 2015;43(8):819-24.

35. Bláfoss R, Micheletti J, Sundstrup E, et al. Is fatigue after work a barrier for leisure-time physical activity? Cross-sectional study among 10,000 adults from the general working population. Scand J Public Health. 2019;47(3):383-91.

36. Bláfoss $R$, Sundstrup $E$, Jakobsen $M$, et al. Are insomnia type sleep problems associated with a less physically active lifestyle? A cross-sectional study among 7,700 adults from the general working population. Front Public Health. 2019;7:117

37. Fehrmann E, Kotulla S, Fischer $L$, et al. The impact of age and gender on the ICF-based assessment of chronic low back pain. Disabil Rehabil. 2018; 41(10):1190-9.

38. Heuch I, Heuch I, Hagen K, et al. Physical activity level at work and risk of chronic low back pain: a follow-up in the Nord-Trøndelag health study. PLoS One. 2017;12(4):e0175086.

39. Pejtersen JH, Kristensen TS, Borg V, et al. The second version of the Copenhagen psychosocial questionnaire. Scand J Public Health. 2010;38:8-24.

40. Netto MB, Barranco ABS, de Oliveira KWK, et al. Influence of anxiety and depression symptoms on the quality of life in patients undergoing lumbar spine surgery. Rev Bras Ortop. 2018:53(1):38-44.

41. Sherrington C, Whitney JC, Lord SR, et al. Effective exercise for the prevention of falls: a systematic review and meta-analysis. J Am Geriatr Soc. 2008:56(12):2234-43.

42. Janssen I, LeBlanc AG. Systematic review of the health benefits of physical activity and fitness in school-aged children and youth. Int J Behav Nutr Phys Act. 2010;7:40

43. May AM, Struijk EA, Fransen HP, et al. The impact of a healthy lifestyle on disability-adjusted life years: a prospective cohort study. BMC Med. 2015;13:39.

44. Choi BK, Verbeek JH, Tam WW-S, et al. Exercises for prevention of recurrences of low-back pain. Cochrane Database Syst Rev. 2010;1: CD006555.

45. Zadro JR, Shirley D, Amorim A, et al. Are people with chronic low back pain meeting the physical activity guidelines? A co-twin control study. Spine J. 2017;17(6):845-54.

46. Lunde L-K, Koch M, Hanvold TN, et al. Low back pain and physical activity-a 6.5 year follow-up among young adults in their transition from school to working life. BMC Public Health. 2015;15:1115.

47. Leboeuf-Yde C, Kyvik KO. At what age does low back pain become a common problem? A study of 29,424 individuals aged 12-41 years. Spine. 1998;23(2):228-34.

48. Sitthipornvorakul E, Janwantanakul P, Purepong N, et al. The association between physical activity and neck and low back pain: a systematic review. Eur Spine J. 2011;20(5):677-89.

49. Qiu F, Liang C-L, Liu H, et al. Impacts of cigarette smoking on immune responsiveness: up and down or upside down? Oncotarget. 2017;8(1):268-84.

50. Abate $M$, Vanni $D$, Pantalone $A$, et al. Cigarette smoking and musculoskeletal disorders. Muscles Ligaments Tendons J. 2013;3(2):63-9.

51. Rasim UI Hasanat M, Ali SS, Rasheed A, et al. Frequency and associated risk factors for neck pain among software engineers in Karachi. Pakistan JPMA J Pak Med Assoc. 2017;67(7):1009-12.

52. Chen B, Li L, Donovan C, et al. Prevalence and characteristics of chronic body pain in China: a national study. SpringerPlus. 2016;5(1):938.

53. Skillgate E, Pico-Espinosa OJ, Hallqvist J, et al. Healthy lifestyle behavior and risk of long duration troublesome neck pain or low back pain among men and women: results from the Stockholm public health cohort. Clin Epidemiol. 2017;9:491-500.

54. Johannes CB, Le TK, Zhou X, et al. The prevalence of chronic pain in United States adults: results of an internet-based survey. J Pain Off J Am Pain Soc. 2010;11:1230-9.

55. Baker KS, Gibson SJ, Georgiou-Karistianis N, et al. Relationship between selfreported cognitive difficulties, objective neuropsychological test performance and psychological distress in chronic pain. Eur J Pain Lond Engl. 2018;22(3):601-13.

\section{Publisher's Note}

Springer Nature remains neutral with regard to jurisdictional claims in published maps and institutional affiliations.

\section{Ready to submit your research? Choose BMC and benefit from:}

- fast, convenient online submission

- thorough peer review by experienced researchers in your field

- rapid publication on acceptance

- support for research data, including large and complex data types

- gold Open Access which fosters wider collaboration and increased citations

- maximum visibility for your research: over $100 \mathrm{M}$ website views per year

At BMC, research is always in progress.

Learn more biomedcentral.com/submissions 